\title{
JOGOS ELETRÔNICOS E EDUCAÇÃO: CONSTRUINDO UM ROTEIRO PARA SUA ANÁLISE PEDAGÓGICA
}

Victor de Abreu Azevedo. Licenciado em Educação Física (CDS/UFSC). Mestre em

Educação (PPGE/UFSC). Membro dos grupos de pesquisa Labomidia e Edumidia (UFSC). Professor da Secretaria Municipal de Educação de Porto Alegre (SMED/POA). Contato: victorazev@gmail.com

Resumo: Este texto descreve trabalho de dissertação em Educação que teve como objetivo propor um roteiro para análise pedagógica dos jogos eletrônicos (JEs). Para atingir esse objetivo, foi realizada uma revisão de literatura sobre JEs tratando de questões como o aprendizado nos JEs, a metodologia de análise de JEs, e as dificuldades para a utilização dos JEs na escola. Posteriormente realizou-se pesquisa de campo com alunos e professores que utilizaram e problematizaram o roteiro proposto. $\mathrm{O}$ roteiro de análise teve boa avaliação dos seus usuários, que apontaram êxito em sua finalidade. Novas pesquisas, agora em situações concretas de uso pedagógico do roteiro para levar JEs para a escola com a mediação de professores, podem contribuir para avaliar e aprimorar o roteiro.

Palavras-chave: análise de jogos eletrônicos, aprendizado, mídia-educação.

\section{ELECTRONIC GAMES AND EDUCATION: BUILDING A TOOL FOR ITS PEDAGOGICAL ANALYSIS}

\begin{abstract}
This text describes a dissertation work in Education that had as objective propose a pedagogical tool for the analysis of electronic games (EGs). To achieve this goal, a literature review of EGs dealing with issues such as learning in EGs, the analysis methodology of EGs, and the difficulties for the use of EGs at school is held. From the data collected by reviewing literature and conducting tests with students and teachers who utilized the tool to analyze EGs, our proposal was developed. The analysis tool had a good evaluation from their users, which showed successful in its purpose. New research in concrete situations of pedagogical use of this tool to get EGs to school with the mediation of teachers can help to assess and improve it.
\end{abstract}

Keywords: analysis of electronic games, learning, media-education.

\section{INTRODUÇÃO}

Este trabalho descreve os resultados de trabalho de dissertação em Educação (Azevedo, 2012) que teve como objetivo principal desenvolver um roteiro para a análise pedagógica dos jogos eletrônicos (JEs). O roteiro resultante deste trabalho tem como proposta servir tanto como uma ferramenta de apoio aos professores interessados em inserir os JEs em suas aulas, como contribuir em futuras pesquisas acerca destes jogos. 


\subsection{As contribuições presentes na revista Game Studies para a análise dos jogos eletrônicos}

Uma das especificidades da pesquisa acerca dos JEs é a dificuldade de associarmos estes jogos com teorias que foram utilizadas para explicar diversos outros artefatos culturais - como jogos, brinquedos, cinema, etc. -, em suas relações com os indivíduos e a cultura em outros contextos sociais, culturais, econômicos e políticos. Esta é a constatação de Aarseth (2003), um dos fundadores da revista internacional Game Studies (gamestudies.org), pioneira na pesquisa dos JEs. Segundo o autor é preciso desenvolver metodologias próprias ao estudo dos JEs que levem em conta as suas especificidades. Pinheiro (2007) também aponta a necessidade do desenvolvimento de uma metodologia para a análise dos JEs. Para o autor, esta metodologia poderia auxiliar a entender, a analisar, a criticar e a produzir JEs. Pinheiro (2007) critica as pesquisas realizadas aos JEs cujos autores não conheciam seu objeto de estudo, e, mesmo assim, os problematizavam apenas a partir de referenciais teóricos não relacionados com os JEs.

Tanto Pinheiro (2007) como Aarseth (2003) apontam a importância de se conhecer a respeito dos JEs ao pesquisá-los. Concordando com os autores, destacamos que a principal forma de se obter conhecimento sobre os JEs é a partir de sua prática. Aarseth (2003) sugere também outras fontes de informação sobre os JEs que podem contribuir ao pesquisador, como a análise de críticas relacionadas ao título analisado e a observação do jogar de outros jogadores.

O trabalho de Konzack (2002) é referenciado como pioneiro na análise sistemática dos JEs. $\mathrm{O}$ autor destaca a existência de sete camadas diferentes nos JEs e que deveriam ser analisadas e aprofundadas de acordo com os interesses da pesquisa e dos conhecimentos do(s) autor(es): hardware, código de programa, funcionalidade, jogabilidade, sentido, referencialidade e sócio-cultura. Segundo Konzack, devido às suas características, os JEs podem ser objeto de investigação de diversas áreas do conhecimento. Para o autor, cada uma destas camadas poderá ser analisada individualmente, mas uma análise completa de um jogo eletrônico (JE) só poderia ser realizada a partir de todas elas, o que necessitaria um trabalho interdisciplinar para que os pesquisadores contemplassem as perspectivas técnicas, estéticas e sócio-culturais dos jogos.

Aarseth (2003) destaca as contribuições do trabalho de Konzack, e também ressalta que, dada a complexidade dos JEs, dificilmente um pesquisador conseguiria aprofundar todas estas camadas. Para Aarseth, nem todas as características dos JEs se apresentariam a todos os pesquisadores, tais como os códigos de programação dos jogos que se encontram inclusos em uma das camadas propostas, nem um pesquisador conseguiria sozinho ter conhecimento necessário para aprofundar a totalidade destas camadas. Para a análise de um JE, segundo o autor, deveriam ser selecionadas e aprofundadas apenas algumas das camadas propostas por Konzack (2002). Estas camadas deveriam ser abordadas junto às demais camadas, e não de forma isolada, o que tornaria a abordagem mais eficiente.

São duas as principais contribuições de Aarseth (2003) à análise de JEs. A primeira é a de demonstrar a importância dos pesquisadores jogarem os títulos que irão analisar. Através deste procedimento conheceriam suas características, bem como as dinâmicas envolvidas nos JEs, como seus desafios e as decisões tomadas pelo jogador para os transpor. Assim compreenderiam os títulos analisados e as ações neles tomadas 
por outros jogadores. A segunda contribuição é a de propor outras fontes de dados para que se compreenda o JE analisado, tais como críticas de especialistas, relatos e/ou observações de outros jogadores com o mesmo título, dicas sobre o jogo, etc., o que traria auxílio ao pesquisador para solucionar os desafios propostos pelo título e também para obter outros pontos de vista que auxiliassem em sua compreensão.

Segundo Consalvo e Dutton (2006), os trabalhos anteriores de Aarseth (2003) e Konzack (2002) perceberam a falta de metodologias para a análise crítica dos JEs, e têm mérito ao apontar que, no mínimo, os pesquisadores deveriam jogar os JEs que analisam, assim como fazem os pesquisadores de filmes e de literatura, que procuram observar atentamente seus objetos. No entanto, de acordo com Consalvo e Dutton, os trabalhos anteriores não apresentaram de forma sistemática os elementos presentes nos JEs que podem auxiliar os pesquisadores em suas análises. Assim, Consalvo e Dutton (2006) propõem um modelo preliminar para a análise crítica dos JEs que amplia os anteriores ao acrescentar elementos importantes existentes nos JEs contemporâneos. Dividem a sua análise então no estudo: dos objetos presentes no inventário do jogo; da sua interface (que apresenta informações necessárias ao jogador); das ações possíveis ao jogador; e da sua jogabilidade (o que envolve as características do jogo).

Malliet (2007) aponta a escassez de referenciais na literatura sobre a metodologia de análise dos JEs. $\mathrm{O}$ autor apresenta um esquema geral de análise estruturado em sete tópicos de interesse: estilo audiovisual; narrativa; complexidade dos controles; objetivos do jogo; estrutura dos personagens e dos objetos; balanceamento entre as ações do jogador e as regras do jogo; e propriedades espaciais do mundo do jogo. Malliet (2007) ressalta que os pesquisadores também podem usar como contribuição às suas pesquisas as já referidas categorias propostas por Consalvo e Dutton (2006) e Konzack (2002), ou ainda enfatizar outros elementos do conteúdo dos JEs, levando sempre em conta as necessidades da sua investigação. $\mathrm{O}$ autor alerta que, ao analisar um JE, o pesquisador, além de estar intensamente envolvido com o jogo, deve reconhecer que muitas decisões metodológicas da sua análise vão ser tomadas ao longo do desenvolvimento da sua pesquisa. Estas decisões estão diretamente relacionadas com os objetivos do estudo e, conseqüentemente, com a relação que os pesquisadores mantêm com os JEs que analisam, levando em conta as suas motivações, seus interesses de conteúdo, e seu nível de experiência com os JEs.

\section{MATERIAIS E MÉTODOS}

A partir de nossa revisão acerca dos JEs e de pesquisas prévias realizadas em escolas, foi desenvolvido um questionário inicial que foi levado aos sujeitos de nossa pesquisa. Era imprescindível para a construção do roteiro que ele fosse testado para posteriormente ser aprimorado pelo pesquisador. O questionário foi dividido em duas partes com o objetivo de ser respondido em dois tempos. Primeiramente os participantes responderiam à parte do perfil, e após jogarem o tempo previsto, responderiam à parte de análise do jogo. As questões de 1 a 19 componentes da primeira parte tratavam do perfil do professor. Foram elaboradas a partir de um questionário anteriormente aplicado em alunos de escolas através do projeto desenvolvido entre os anos de 2008 e 2010 (Cruz et. al., 2011).

A segunda parte tratava da análise do JE. Foi elaborada a partir da revisão de literatura sobre JEs e da experiência de utilização de JEs em escolas pelo referido 
projeto. Esta parte, após modificações ao longo da pesquisa, deu origem ao roteiro proposto. Destacamos a questão 26, a mais extensa, e que aborda na forma de itens de análise os aprendizados possíveis aos JEs segundo Gee $(2004,2009)$. Ao final do questionário duas questões foram elaboradas tendo em vista a avaliação do questionário e de sua intencionalidade pelo participante da pesquisa. $\mathrm{O}$ conjunto das duas respostas avaliativas do questionário com a entrevista posterior dos participantes nos trouxe maior precisão na avaliação do roteiro proposto em nossa pesquisa.

Em relação aos JEs, a pesquisa envolveu a observação e a análise de títulos de JEs escolhidos segundo critérios definidos previamente para a pesquisa. Também incluiu consulta a sites e revistas especializadas de JEs, de acordo com as sugestões de Aarseth (2003). Estes procedimentos acerca dos JEs nos trouxeram diferentes pontos de vista e informações acerca do objeto pesquisado, nos auxiliando na discussão a seu respeito e na escolha de títulos para esta pesquisa. A revisão bibliográfica, a observação e análise de títulos, assim como a consulta a sites e revistas especializadas, nos trouxeram elementos para a elaboração de um questionário que foi aplicado em diferentes contextos e participantes, que continham perfis variados ao longo das etapas da pesquisa.

Em sua etapa de elaboração inicial, o questionário foi testado por três participantes que eram jogadores, mas que não participaram das etapas pré-teste e teste, pois não eram estudantes de cursos de licenciatura ou professores em atuação, públicoalvo de nossa pesquisa. Após os testes iniciais, foi elaborado um questionário composto por perguntas fechadas, abertas e semi-abertas (Labes, 1998) e dividido em duas partes, sendo a primeira relacionada com o perfil do respondente, e a segunda à análise com finalidade pedagógica do JE jogado pelos participantes.

Posteriormente a elaboração do questionário, três JEs de gêneros interativos distintos foram selecionados e levados para os participantes das etapas pré-teste e teste jogarem e analisarem a partir do questionário. Os participantes jogaram um período prédeterminado de 45 minutos os títulos Sim City 2000 (Maxis, 1994), The Secret of Monkey Island (Lucasfilm games, 1990) e Fallout (Interplay entertainment, 1997).

O questionário foi aplicado em duas etapas. Primeiramente um pré-teste (Lakatos, 1992; Labes, 1998) foi realizado com 10 alunos de uma disciplina de licenciatura que tematizava o uso de mídias na educação. Um pesquisador de JEs foi convidado para participar junto a este grupo e contribuir a pesquisa.

Após a análise dos dados coletados no pré-teste, e da reformulação do questionário segundo os resultados obtidos nessa etapa, a pesquisa teve continuidade por meio de um teste (Lakatos, 1992; Labes, 1998). Este teste envolveu dois grupos distintos de professores em atuação em escolas públicas presentes a cidade de Porto Alegre/RS. O teste foi conduzido então com um grupo de três professores que não jogam JEs cotidianamente, e um grupo de três professores que jogavam cotidianamente JEs. Cada um dos três títulos foi jogado por um jogador e um não jogador. A distinção em dois grupos no teste foi essencial para obtermos diferentes pontos de vista sobre a nossa proposta. Todos os participantes autorizaram a utilização dos dados coletados através do "Termo de Consentimento Livre e Esclarecido", preservando-lhes sua identidade.

Após a aplicação dos questionários, entrevistas parcialmente estruturadas (Laville; Dionne, 1999) foram realizadas junto aos grupos pré-teste e teste. As entrevistas foram gravadas e transcritas pelo pesquisador. A análise dos dados coletados por meio dos questionários e das entrevistas nos trouxeram elementos para elaborar uma 
proposta de roteiro de análise com finalidade pedagógica dos JEs. O roteiro resultante destas etapas encontra-se na sequência.

\section{ROTEIRO PARA ANÁLISE PEDAGÓGICA DOS JEs}

O roteiro gerado pela aplicação do questionário e entrevistas tomou a seguinte forma e está sendo apresentado aqui para que seja explorado pelos professores e pelos pesquisadores interessados em investigar essa temática.

I) Descrição das características gerais do título analisado:

01. Título do JE

02. Faça uma sinopse (ou um resumo) da história do JE analisado:

03. Quais são as ações possíveis de serem realizadas no JE para o seu desenvolvimento? Pode marcar mais de uma opção:

( ) saltar ( ) atirar ( ) utilizar itens ( ) manipular objetos ( ) dirigir

( ) capturar ( ) pilotar ( ) lutar ( ) nadar ( ) voar ( ) esquivar ( ) conversar ( ) tocar instrumentos musicais ( ) dançar ( ) realizar movimentos esportivos ( ) coletar

( ) administrar recursos ( ) construir ( ) apostar ( ) correr ( ) fugir ( ) solucionar enigmas

( ) responder perguntas ( ) Realizar movimentos em sincronia com a música

( ) Outros

04. Quais são os objetivos principais existentes no JE (por ex.: construir cidades, administrar recursos, derrotar inimigos, resolver problemas, etc.)?

05. Quais as regras que você percebe que existem no jogo analisado?

06. Comente as características visuais e sonoras do JE analisado:

07. Ao analisar diversos títulos que obtiveram sucesso junto à crítica especializada e aos jogadores, Gee $(2004$; 2009) aponta diversos princípios de aprendizagem que encontram-se incorporados junto aos JEs. Abaixo são levantados os principais princípios de aprendizagem existentes nos JEs segundo este autor. A partir de sua experiência com o título analisado verifique quais destes princípios são encontrados nele preenchendo "sim" ou "não" para as alternativas e comentando a sua escolha.

a) Identidade:

É possível assumir e interpretar outras identidades já formadas e que são oferecidas pelo jogo?

( ) $\operatorname{sim}($ ) não. Comente.

O jogador pode construir e desenvolver um novo personagem desde o início do jogo?

( ) $\operatorname{sim}($ ) não. Comente

b) Produção:

V. $10 \mathrm{~N}^{\mathrm{o}} 3$, dezembro, 2012 
O jogo permite diferentes tomadas de decisões por parte do jogador que afetam em seu contexto e seu desenvolvimento?

( ) $\operatorname{sim}($ ) não. Comente

O jogo disponibiliza ferramentas que permitem ao jogador customizá-lo a partir da edição de cenários, da criação de fases e/ou da construção de novos jogos?

( ) $\operatorname{sim}($ ) não. Comente

c) Riscos:

O jogo possibilita que a partir de erros anteriores, o jogador reflita e crie novas estratégias para vencer o desafio?

( ) $\operatorname{sim}$ ( ) não. Comente

O mecanismo de salvar do jogo incentiva ao jogador explorar e correr riscos no jogo?

( ) $\operatorname{sim}($ ) não. Comente

d) Customização:

É possível escolher os níveis de dificuldade do jogo?

( ) $\operatorname{sim}($ ) não. Comente

É possível escolher as habilidades que se deseja desenvolver nos personagens do jogo?

( ) $\operatorname{sim}($ ) não. Comente

e) Agência:

O JE proporciona ao jogador a sensação de controle sobre as ações e as decisões que toma ao jogar?

( ) $\operatorname{sim}($ ) não. Comente

f) Boa ordenação dos problemas:

Os objetivos mais fáceis são apresentados ao jogador primeiramente em relação aos mais difíceis, facilitando assim a solução dos últimos?

( ) $\operatorname{sim}($ ) não. Comente

g) Desafio e consolidação:

O JE oferece a oportunidade de o jogador repetir diversas vezes os problemas por ele apresentados até que estes sejam aprendidos, e, só posteriormente, apresenta novos desafios ao jogador?

( ) $\operatorname{sim}($ ) não. Comente

h) Informação "na hora certa" e "a pedido":

O JE oferece informação no momento necessário para o jogador por meio do contexto do jogo (por ex.: a fala de um personagem que oferece dicas para a solução de um enigma)?

( ) $\operatorname{sim}($ ) não. Comente

O JE oferece informação ao jogador quando ele a solicita (por ex.: a possibilidade de acessar um tutorial sobre os comandos do JE)?

( ) $\operatorname{sim}($ ) não. Comente

i) Sentidos contextualizados:

O JE contextualiza os significados das palavras a ele veiculadas através de ações, imagens e diálogos a elas relacionadas?

( ) $\operatorname{sim}($ ) não. Comente

V. $10 \mathrm{~N}^{\mathrm{o}} 3$, dezembro, 2012 
j) Frustração prazerosa:

Os problemas a serem resolvidos no jogo são desafiadores e motivantes?

( ) $\operatorname{sim}($ ) não. Comente

k) Pensamento sistemático:

O JE incentiva o jogador a pensar sobre as relações entre os eventos, os fatos e as habilidades nele existentes?

( ) $\operatorname{sim}($ ) não. Comente

O JE incentiva o jogador a refletir sobre a repercussão de suas ações tanto para a evolução do jogo (por ex.: salvar ou não um personagem ferido; escolher de que forma administrar recursos; etc.), como para os seus demais jogadores (por ex.: jogos para diversos jogadores online)?

( ) $\operatorname{sim}($ ) não. Comente

1) Explorar, pensar lateralmente, repensar os objetivos:

O JE incentiva o jogador a explorar o jogo detalhadamente antes que ele siga em direção a realização do próximo objetivo?

( ) $\operatorname{sim}($ ) não. Comente

A exploração do JE auxilia o jogador a repensar os objetivos gerais nele presentes?

( ) $\operatorname{sim}($ ) não. Comente

m) Ferramentas inteligentes e conhecimento distribuído:

O JE apresenta ferramentas inteligentes (por ex.: personagens controlados pelo jogador ou pelo computador) que emprestam seus conhecimentos e habilidades ao jogador (por ex.: perícia com armas de longa distância; habilidade de utilizar magias), de modo que o jogador precisa apenas saber quando e como utilizar os conhecimentos destas ferramentas para enfrentar os desafios encontrados?

( ) $\operatorname{sim}$ ( ) não. Comente

Neste JE, os jogadores podem auxiliar uns aos outros compartilhando os seus conhecimentos sobre o jogo, assim como as habilidades de seus personagens, em prol de um objetivo comum (por ex.: jogos de tiro com visão em primeira pessoa online onde cada jogador atua dentro de uma equipe)?

( ) $\operatorname{sim}($ ) não. Comente

n) Equipes transfuncionais:

Este JE permite que seus jogadores trabalhem em equipes onde cada jogador age de acordo com as habilidades de seu personagem, assim como das necessidades e dos objetivos da equipe?

( ) $\operatorname{sim}($ ) não. Comente

II) Refletindo sobre a utilização pedagógica do JE: um exercício de simulação do uso pedagógico do título analisado no espaço escolar.

08. Conteúdos que podem ser desenvolvidos a partir da utilização do JE.

a) Qual(is) disciplina(s) escolares poderia(m) abordar este JE?

b) Qual(is) conteúdo(s) que poderia(m) ser abordado(s) a partir deste JE?

09. Condições necessárias para a utilização do JE na escola

V. $10 \mathrm{~N}^{\mathrm{o}}$ 3, dezembro, 2012 
a) Quais são os recursos materiais e humanos disponíveis na escola que podem propiciar o uso pedagógico deste JE?

b) Destacando-se a relação entre o tempo necessário para se jogar este JE, com o tempo disponível para as suas aulas, como você planejaria a utilização deste título?

10. Utilização pedagógica do JE

a) Tendo em vista os princípios de aprendizagem existentes no título analisado, assim como os recursos materiais e humanos e o tempo disponível, como você utilizaria este JE em suas aulas?

b) Quais atividades poderiam ser desenvolvidas a partir deste JE nas aulas da sua escola?

( ) Produção de textos sobre o JE

( ) Cumprimento de objetivos pré-determinados pelo professor dentro do JE

( ) Discussões realizadas a partir do JE

( ) Produção de materiais e realização de atividades que abordem o JE

( ) Outras atividades, quais?

c) Como seriam avaliadas as atividades desenvolvidas a partir deste JE?

( ) Discussão das atividades realizadas a partir do JE

( ) Avaliação do aprendizado adquirido por meio de provas

( ) Realização de trabalhos/projetos

( ) Avaliação por meio da análise do jogar dos alunos

( ) Outros, quais?

\section{CONSIDERAÇÕES FINAIS}

Ao contrário de nossas expectativas iniciais, dada a dificuldade de se analisar um JE a partir de uma finalidade pedagógica, o roteiro proposto teve boa aceitação de seu público, tanto entre os professores em formação, como, principalmente, entre os professores que se encontram em atuação. Os professores apontaram que o roteiro os auxiliou a compreender o título analisado e a simular o seu uso pedagógico em sala de aula. A metodologia utilizada para a pesquisa, com sua revisão bibliográfica, a análise prévia dos títulos pelo pesquisador, e a realização de etapas pré-teste e teste obteve bons resultados, trazendo opiniões diversas de alunos, professores, jogadores de JEs e de não jogadores, contribuindo a construção do roteiro. O contexto de aplicação do roteiro durante a pesquisa foi diferente em relação ao contexto real de uso de tal roteiro pelo professor. Comparando a utilização do roteiro no ambiente de pesquisa, com seu tempo de aplicação e recursos reduzidos, com as condições de trabalho docente, podemos levantar algumas hipóteses.

Ao planejar suas aulas com o JE, o professor terá hipoteticamente mais tempo disponível para jogar, analisar, refletir e planejar aulas em conjunto com o roteiro em seu uso pedagógico, como apontou o professor A. O professor também poderá dispor de outros recursos para a análise de JEs, como dicas de outros jogadores online/offline sobre os JEs que quer analisar e utilizar em suas aulas, como sugere Aarseth (2003). O professor pode incluir como fonte de referência para obtenção de conhecimentos sobre JEs os seus próprios alunos, tanto a respeito do título que quer analisar, como a respeito dos JEs em geral. O professor também poderá ter acesso ao uso de dicionários e/ou 
tradutores online de línguas estrangeiras caso tenha dificuldades na compreensão do idioma em que se encontra o título.

Como apontam professores participantes em nossa pesquisa, o planejamento e a análise do JE em conjunto com diferentes disciplinas escolares a partir do roteiro proposto auxiliaria em sua compreensão, na ampliação de suas possibilidades pedagógicas, assim como ampliaria o espaço e tempo para utilizar o JE. A análise e o uso (multi/inter)disciplinar dos JEs potencializaria assim o uso dos recursos materiais e humanos existentes na escola para a abordagem pedagógica do JE.

$\mathrm{O}$ roteiro proposto, como bem observa o professor $\mathrm{B}$, pode ser aprimorado a partir de novas e necessárias contribuições de acordo tanto com as necessidades percebidas pelos seus usuários, como pelas levantadas pelos JEs que serão analisados por ele, tendo em vista a rápida e constante evolução desta forma de jogar. A utilização do roteiro pelos professores, assim como a realização de pesquisas que acompanhem o trabalho destes professores com os JEs, podem trazer diversas contribuições provindas de diferentes contextos ao roteiro, ampliando assim a sua eficiência em relação ao seu propósito final, viabilizar os JEs na escola.

\section{REFERÊNCIAS BIBLIOGRÁFICAS}

AARSETH, E., 2003. Playing Research: Methodological approaches to game analysis [online]. In: Anais do Spilforskning.dk Conference, Dinamarca. 2003.

AZEVEDO, Victor de Abreu. Jogos eletrônicos e educação: construindo um roteiro para sua análise pedagógica. Santa Catarina: Florianópolis: PPGE/UFSC, 2012, 228p, Dissertação de mestrado.

CONSALVO, M.; DUTTON, N., 2006. Game analysis: Developing a methodological toolkit for the qualitative study of games. Revista Game Studies, v. 6, ed. 1. Disponível em: http://www.gamestudies.org/0601/articles/consalvo_dutton [Acessado em 7/agosto/2010].

CRUZ, D. M.; AlBUQUERQUE, R. M.; AZEVEDO, V. A. RPG Maker como ferramenta pedagógica: produzindo jogos eletrônicos com crianças. In: Computer on the Beach, 2. Florianópolis, 2011.

GEE, James. Paul. What video games have to teach us about learning and literacy. New York: Palgrave Macmillan, 2004.

GEE, James Paul. Video Games, Learning, and "Content". In: Miller, Christopher Thomas (org.). Purpose and Potential in Education. Nova Iorque: Springer, 2008

GEE, J., P.. Bons videogames e boa aprendizagem. Revista Perspectiva, Florianópolis, v. 27 n. 1, pp. 167-178, jan./jun. 2009.

Fallout. Beverly Hills: Interplay Entertainment. PC. 1997.

KONZACK, L. (2002). Computer game criticism: A method for computer game 
analysis. Proceedings of the Computer Games and Digital Culture conference, Tampere, Finland, 2002.

LABES, Emerson Moises. Questionário: do planejamento à aplicação na pesquisa. Chapecó: Grifos, 1998.

LAKATOS, Eva Maria; MARCONI, Marina de Andrade. Metodologia do trabalho científico: procedimentos básicos, pesquisa bibliográfica, projeto e relatório, publicações e trabalhos científicos. $4^{\text {a}} \backslash$ ed. São Paulo: Atlas, 1992.

LAVILLE, Christian; DIONNE, Jean. A construção do saber: manual de metodologia da pesquisa em ciências humanas. Porto Alegre: Artes Médicas Sul Ltda; Belo Horizonte: UFMG, 1999.

The Secret of Monkey Island. PC. San Francisco: Lucasfilm Games. PC. 1990.

MALLIET, S., 2007. Adapting the Principles of Ludology to the Method of Video Game Content Analysis. Revista Game Studies v. 7 ed. 1. Disponível em: http://gamestudies.org/0701/articles/malliet [Acessado em 2/ agosto/2010].

Sim City 2000. Emeryville: MAXIS; PC. 1994.

PINHEIRO, Cristiano Max Pereira. Apontamentos para uma aproximação entre jogos digitais e comunicação. 201 f. Tese (Doutorado em Comunicação Social) Programa de Pós-Graduação em Comunicação - Pontifícia Universidade Católica do Rio Grande do Sul, Porto Alegre, 2007. 